\title{
1. Introduction: inspecting health and safety management and the consequences of restructuring in the modern world of work
}

\section{INTRODUCTION}

According to ILO figures, ${ }^{1}$ despite advances in occupational medicine and safety technology, the global burden of work-related mortality, injury and disease remains huge - and far in excess of that arising from more publicized causes of harm, such as armed conflicts. The ILO estimates, for example, that some 2.2 million workers die every year as a result of work-related ill-health and injury. Of these, 350,000 deaths are attributable to accidents at work, while the rest are caused by occupational ill-health. It further estimates that there are an additional 264 million non-fatal accidents each year and 160 million people with work-related illnesses. It calculates the economic cost of this loss as worth 4 per cent of global GDP or \$1.25 trillion US dollars (Hämäläinen et al. 2005). It also acknowledges that the vast majority of these deaths are avoidable and preventable.

Most of this work-related death, illness and injury occurs in developing and newly industrializing countries, but the figures also provide no cause for complacency among the more advanced economies. For example, in the UK, despite its more than 200 hundred years of regulation on health and safety at work, and with one of the better records internationally, there are still over 200 deaths each year from ill-health or injuries related to work. In addition, more than 20,000 people leave employment as a result of workrelated injury or illness, and more than two million suffer from ill-health, which in their view was caused or made worse by their work, leading to the loss of more than 30 million working days each year and costing the equivalent of 1-3 per cent of GDP. This pattern is repeated in other advanced economies, with many performing much worse. Moreover, these

1 See: Hämäläinen et al. (2005). Also: http://www.ilo.int/public/english/ protection/safework/accidis/globesti.pdf. 
numbers only represent what is officially recognised, while many reports and studies in different countries point to the substantial under-notification of occupational injuries and diseases (see for example Lejeune and Vientot 2006). Overall the problem remains substantial and significant internationally. This represents a massive burden of human suffering but there is no great mystery surrounding its cause, which is primarily the result of failures of management in the discharge of employers' legal duties to protect the health and safety of their workers.

Historically, efforts to prevent illness and injury at work have come from a combination of political activities, regulatory intervention, labour market action, professional and managerial initiative and expertise as well as from the impact of technological innovation and economic restructuring. In most countries the role of regulatory inspection and enforcement has been central to these efforts. A recent parallel development, partly as a consequence of recognition of some of the limitations of regulatory strategies, has been a greater emphasis on attention to how employers manage the work environment as a means to further improve health and safety at work. Despite this increased profile for management, there is nothing in global or national occupational health and safety (OHS) statistics to support the notion that such a focus serves as a justification for reduced regulation and regulatory surveillance, despite suggestions to this effect by neo-liberal economists. The focus on management nevertheless clearly does have implications for regulatory surveillance and the way it is undertaken. Such implications have become even more significant in recent decades because of the enormous changes in the nature of work and its organization, as well as in the structure of the economy and the labour market. These changes present challenges for the traditional model of regulatory inspection of health and safety at work that was essentially derived to address the challenges posed by the exploitation of labour in emergent industrializing societies of the nineteenth century.

This book is concerned with exploring the role of labour inspection in contemporary OHS regulatory regimes. It presents an analysis of how labour inspectorates in several countries inspect and seek compliance with regulatory provisions on health and safety management in changing economic, political and regulatory scenarios. It includes findings from recent empirically based field studies on the activities of labour inspectors in Australia and Sweden and synthesis of secondary data on the role of labour inspection in the Canadian province of Québec, in France and in the UK. Together these national case studies highlight three main issues. First, they throw useful light on the role of labour inspection in improving health and safety in modern work settings, through requiring better approaches to its systematic management. But second, they also demonstrate a range of 
difficulties that labour inspectors experience in achieving this and the limitations of traditional inspection strategies and techniques in this respect. Third, they identify the main causes of such difficulties to be located within the context of recent trends in the structure and organization of work and the political and economic drivers behind them. The chapters presenting the national case studies provide a detailed and analytical discussion of these issues from a variety of different perspectives and outline the strengths and weaknesses apparent in labour-inspection strategies to address them. These issues and their implications are summarized in the book's penultimate chapter, while its concluding chapter presents a more comparative international analysis of the political and economic challenge to the role of labour inspection in the restructured world of work in advanced market economies.

\section{WHY FOCUS ON LABOUR INSPECTION?}

In most countries the surveillance of compliance with measures for the protection of the health, safety and welfare of employees is the remit of inspectorates created for this purpose during an earlier period of industrialization. In some, their role has extended beyond this, to embrace the surveillance of other aspects of pay and working conditions and to becoming involved in industrial relations issues. But regardless of the extent of their coverage, intervention by state inspectorates, specifically created to protect the health, safety and welfare of labour from exploitation by profit-seeking capital, is a feature common to the development of most industrial societies. Simply put, the origins of labour inspection are linked to the introduction of regulatory means to eliminate or at least reduce hazards at work, in which employers were charged with various legal duties in relation to protecting the health and safety of their employees and providing for their welfare. Labour inspection was a result of a political recognition that to be effective, legal measures designed to protect employees could not be left entirely to voluntary compliance from duty-holders, but required some form of surveillance and sanction - a role that, in most jurisdictions, was filled by labour inspectorates with inspection and enforcement powers, including recourse to the courts to ensure their application.

Of course, this is an historical oversimplification that masks a more complex reality at the heart of the social values of industrial societies. It is essentially for this reason that the activity of labour inspection has long held a particular fascination for social reformers, theorists and researchers 
alike. This remains as true today as it did during the nineteenth century and it is with this reality that this book is concerned.

\section{THE PANACEA OF MANAGEMENT}

The distinguishing feature of the development of regulation on OHS in most countries in recent decades has been its shift from a prescriptive approach in which legally binding detailed, technical standards outlining specific safeguards were set, to a process-based approach in which improved management of health and safety is sought. Albeit in more general and often performance-related forms, specification standards for the regulation of OHS outcomes remain in force. However, to them have been added mandatory requirements on the process through which employers are to achieve compliance with these material regulatory requirements. As many observers have noted, this is evident in regulatory measures such as the EU Framework Directive 89/391 'on the introduction of measures to encourage improvements in the safety and health of workers at work', and although there is considerable variation in origin and detail, its development is also evident at national level in most advanced market economies from the 1970s onwards (see, for example, Frick et al 2000).

At the same time, and also at both national and international levels, there has been a parallel development of voluntary standards and guidelines on health and safety management systems by standard-setting bodies, large organizations and commercial operators. As Frick et al (2000) have argued, the origins of these voluntary approaches to health and safety management can be dated from safety movements in the US in the early 1900s (Aldrich 1997; Dwyer 1991; Gaupset 2000) and also related to post-war concern with the management of quality more generally - which had a profound impact on organizational management more widely, and OHS management (OHSM) more specifically.

Voluntary standards on quality were initially product-based, but moves towards process-based quality eventually led to the emergence of standards such as BS 5750 in the UK in 1979. In parallel, the post-war development of quality management, originating in American-influenced techniques to achieve continuous improvement in Japanese production, led to the subsequent introduction of Total Quality Management into the US and elsewhere from the 1970s onwards (Deming 1986). Together with process standards these changes, originally located in improving the process of production, were quickly extended across other management functions within organizations, leading standards institutions to follow the model 
provided by BS 5750 in the introduction of the ISO 9000 series internationally in 1987 . When in the 1990s industry was required to focus on controlling its impact on the environment, a similar pattern of events saw the introduction of BS 7750, which formed the model for the international ISO 14000 series that followed. Much has been made of ISO standards in the literature of modern business practice as well as in public discourse. However, as Thebaud-Mony will discuss in detail in Chapter 11, it needs to be remembered that they and the processes that create them are also social constructions. As she will argue in greater detail, they are therefore by no means entirely free from the dominant values and interests of the bodies that create and adopt them.

These observations are important when evaluating the influence of voluntary approaches on regulatory standards for health and safety management, because by the time wider ISO and other management standards were being introduced, a host of national and corporate systems embracing voluntary standards for managing health and safety were also in operation. In 1998 Dalrymple et al were able to identify more than 30 such standards, guidance documents and codes of practice on health and safety management systems internationally. Since that time these instruments have continued to proliferate. Most require similar elements based around a health and safety policy: the organization and arrangements to plan and implement its objectives, the means to measure performance, as well as to investigate, respond, audit and review performance.

There is little doubt that the discourse behind the developments in voluntary standards has also exercised a powerful influence on the emerging regulation of a systematic OHSM. In combination, these two trajectories provide a framework for current approaches towards regulating OHSM. In this approach, traditional specification standards are overlaid by other standards emphasizing a duty to manage the processes involved in order to meet required outcomes. More than this, however, advocacy of such notions of management often goes well beyond its efficacy as a means of meeting prescriptive legal standards and claims a usefulness in its own right - as an approach to achieving continuous improvement in organizational OHS standards and performance in which externally derived prescriptive standards may be progressively replaced by those better suited to organizational needs. Here too, as Thébaud-Mony points out in Chapter 11 , we perhaps need to be a little cautious in our understanding of exactly whose needs are best served in this process, especially in a changing world of work.

In practice, the extent of the implementation of such approaches to OHSM varies considerably. But the central importance of managing workplace risks in modern 'regulated self-regulation' (to use the term coined by 
Wilthagen (1994) to describe these regulatory approaches) is clear and it is further evident that it has significant implications for inspection, not least being the fact that inspecting the management of (the quality of) OHS is a very different task from surveillance of compliance with material OHS regulatory provisions.

However it is equally important to bear in mind that the conceptualization of 'managing health and safety' that has been developed both by voluntary and regulatory means makes some assumptions about the nature of the organizations to which it is supposed to apply. Again to oversimplify somewhat, these assumptions are largely based around the existence of an organizational model with both the will and the capacity to manage the quality of health and safety at work. But a host of studies demonstrate that, outside of larger organizations, such model organizations are in fact far from the norm. Moreover, trends in the restructuring of work may make this model even less relevant to an increasing proportion of worksites and workers. The consequence of this for inspection strategies and practice that focus on achieving health and safety management is therefore also a central concern of the following chapters.

\section{THE DIFFICULTY OF ORGANIZING - AND SUPERVISING - EFFECTIVE OHS MANAGEMENT}

Studies that have shown the limited capacity of firms to utilize effective approaches to OHS management have mostly focussed on the lack of OHS awareness, competence and resources to manage risks at work in small enterprises (see for example, overviews by Eakin, Lamm and Limborg 2000, and by Walters 2001). However, there is also evidence that the management of OHS is frequently ineffective in larger organizations too. Such organizations may have many procedures, meetings and assessments, but these are usually poorly integrated in the general management of the organization and therefore only partially effective in preventing or reducing OHS risks.

For example, in Nordic accounts this lack of integration into mainstream organizational management has been described as the 'sidecar effect' of OHS activities (Frick 1994, ch 3). Numerous inquires into workplace fatalities have also shown how fatal 'accidents' are frequently the results of systematic shortcomings in how OHS is managed, even in organizations with otherwise advanced production management (for example, Hopkins 2000, AV 2003, and Beaconsfield 2009).

The systematic, competent and well-resourced management of OHS required by regulation and specified in voluntary standards for OHSM 
systems requires a considerable investment from employers (Frick 2004). The need for organizational development is also described in documents on voluntary OHSM systems (Bluff 2003). An important aspect of the difficulty in managing the quality of the work environment is that this OHSM like other forms of quality control - is, by definition, never final. Effective OHSM cannot simply be achieved by establishing and implementing procedures. There will always be a need for self-critical auditing of how management achieves its objectives, and for continuous improvement. This is why voluntary OHSM systems, like other quality management systems, require this secondary learning loop (Dalrymple et al. 1998). Such requirements are also found in the Swedish OHSM regulations, the British HSG (65) OHSM guidance and in Australian OHSM standards, although they are curiously absent from the Framework Directive 89/391/EEC.and from Québec's 'Prevention Programme'.

With or without secondary learning through auditing and review, effective management of OHS thus nearly always requires employers to develop measures to address OHS risks. To supervise and enforce OHSM regulations effectively, labour inspectorates therefore have to find ways to influence duty-holders to build better capacity to manage risks at their workplaces. Influencing how employers achieve this through improving the organization and management of their operations in ways that take full account of OHS risks may require different approaches to inspection to those with which traditional inspection of technical risks have been addressed. In the national case studies that follow, we explore the ways that regulatory inspection meets such challenges and with what effects in the countries we have studied.

\section{THE CHANGING WORLD OF WORK}

As industrial societies evolved into post-industrial societies and onwards towards 'globalized' advanced market economies, the leitmotif of their development has been not so much the exploitation of the health and safety of labour in their factories, mills and mines but rather the phenomenon of change. Work for many has become much less obviously physically hazardous, but at the same time more precarious, and prone to the uncertainties associated with its restructuring and reorganization, with its intensification and increased insecurity, and with the consequent 'flexibility' demanded of the workers involved. In this changing environment, certainties associated with an employment relationship bounded by the legal nexus of the contract of employment and the industrial relations procedures of large unionized workplaces are no longer the norm. 
Instead, for many, a growing set of uncertainties are associated with their work for smaller contractors at second or third level positions in complex supply chains and networks for production and service. In these situations outsourcing is used to assist downsized businesses jockey for market positions and dictate favourable price and delivery requirements to others for products and services that often they formerly supplied themselves. The losers in the so-called 'new economy', evident in most restructured postindustrial societies, are usually those at the periphery of the economic networks thus created - the workers with little labour market power, either from their individual position or their collective strength, who work in businesses in weak market positions that are subject to the price and delivery dictates of the economically more powerful.

Not surprisingly, this changing economic scenario has presented 'new' risks for workers. But they are far less the results of 'new' hazards (although these, such as those arising from the implementation of new technologies, continue to occur), as much as they are the consequence of poorly managed exposures in new work scenarios. Research on the health effects of modern work patterns demonstrates that this is as true for the workers who bear the brunt of change resulting from restructuring in large public or private sector organizations, as it is in different ways, for the vulnerable workers at the weak end of supply chains. In both cases, poor risk management (or the absence of risk management) creates exposures to risks to health or safety. This is so, whether they result from ignorance on the part of employers and management concerning the health effects of restructuring and, therefore, the absence of policies to ameliorate them, or from the acknowledged challenges to OHSM presented by small firms, sub-contracting and multiemployer worksites. In all cases, the psychosocial impact of a combination of work insecurity and its intensification results in a rise in the incidence of stress-related ill-health conditions associated with work, while at the same time those structural changes make more traditional risks more difficult to manage.

These problems are further complicated by the fact that traditional conceptualizations of the risks of the work environment are organized around a technical/medical/scientific model that is largely derived from the industrial era. While perfectly serviceable for addressing the amelioration and control of exposures encountered in industrial work environments, this model is less useful when dealing with the risks of the modern workplace that arise as a consequence of decisions about the way in which work is restructured and organized to fit current business models. The merging of notions of 'health and safety' with wider conceptualizations of working conditions and work organization in ways that usefully account for these structural and organizational factors that contribute significantly to the 
underlying causes of the health effects of modern work is a difficult concept to grasp for all traditional actors involved in preventive health and safety. This is true, whether they are professional practitioners, managers, trade union representatives or labour inspectors and, moreover, they receive little encouragement to engage with these issues from managerial colleagues who often view such attempts as encroachments upon their own territories.

\section{LABOUR INSPECTION AND CHANGE}

From the perspective of labour inspection then, these situations present challenges to traditional practice. Increasingly restructured work organization makes formerly accessible work activities more difficult to reach for labour inspectors, both literally and figuratively. They may be literally more difficult for labour inspectors to locate physically and stretch their limited resources to reach and intervene. At the same time, figuratively they present more complex situations in which inspectors must determine the nature and extent of legal responsibilities and recommend suitable preventive strategies. They also represent complex situations in which the root causes of potential ill-health and injuries may lie, not with proximal non-compliance with mandatory OHS standards in relation to materials and plant, but with more remote aspects of the way in which work has been organized and ultimately with the price and delivery constraints that have influenced this. Both inspectors and their peers, as we have noted, also may judge these situations as being beyond the bounds of their legitimate intervention. Even when this is not so, such problems of organization require inspectors to move beyond checking compliance with prescriptive standards and into less familiar territory, in which they must strive to achieve a better understanding of what lies behind the management (or non-management) of OHS within the organizations they inspect. Again, the success of such a reorientation is not helped by restructuring in which management responsibilities for health and safety may be complicated and obscured by outsourcing, sub-contracting and generally by managerial fragmentation.

In most advanced market economies all this has taken place against a wider societal backdrop in which notions of work, the collective and individual rights of labour, and the public understanding of risk have been subject to considerable redefinition as nation states have struggled to come to terms with the effects of globalization and economic competition. Since the end of the 1970s neo-liberal economic and political strategies have dominated national and international approaches to addressing these issues. Recourse to traditional approaches to the protection of labour in such a political economy has been undermined by the withdrawal of the 
state from an overt role in regulating the economy while at the same time the power of organized labour has been substantially weakened by labour market shifts, economic restructuring and political assaults.

Several features of this reconfiguration have important implications for labour inspection. For example, reduced trade union membership and the weakening of organized labour is partly a result of the demise of industrial sectors in which it was once strong, such as mining, heavy industry and manufacturing, and partly a consequence of a failure to achieve anything like the same extent of organization in emerging sectors, occupations and workers that characterize the new economy. During the development of the industrial economy, traditional safety concerns associated with work in the hazardous industries where trade unions became strong were of common interest both to trades unions, and to regulatory inspection - as well as, to some extent, to the interests of larger employers and their organizations. The post-war consensus and corporatism that characterized industrial economies in the second half of the twentieth century allowed for a closely integrated and mutually supportive institutional relationship between these interests and the resulting plethora of tripartite structures for the consensus-based governance of health and safety were evidence of this in many countries. But in the restructuring that has taken place during the past 30 years a growing proportion of workers and their employers have become increasingly distanced from the remit of the remnants of such tripartitism. At the same time, as political and economic power has shifted in favour of capital, regulators and regulatory inspection are obliged to operate in what neo-liberal politicians have described as a more 'business friendly' environment, in which there is political enthusiasm for deregulation in order to remove perceived 'burdens on business', weak labour organization, little appetite for new regulation, and greater emphasis on the application of self-regulatory, market-based solutions and voluntary standards for health and safety at work. In addition, over the same period, there has been a parallel reduction in the resources available to regulatory inspection in most countries.

The strong emphasis on managerialism, referred to previously, in both the voluntary and regulatory approaches to health and safety, emerged from these developments. This is both predictable - given the shift in the balance of power between organized labour and capital, the dominance of neo-liberal political and economic approaches to governance, and increased attention to psychosocial risks that can only be handled through improved management - and somewhat paradoxical, because in the restructured work scenarios thus created, OHS issues are in many respects more difficult to manage than was formerly the case. For example, such situations frequently do not subscribe to neatly constructed situations in 
which the nature of the relationships between workers, their supervisors and their managers are easy to discern and where it is possible to achieve effective flow of essential health and safety information between them, or to ensure it is acted upon appropriately; where the generation of a corporate safety culture and the engagement of all workers with it is possible; or where there are sufficient resources to provide the necessary skills and aptitudes to manage OHS properly in the places where such management might matter. This, in combination with the changed risk profile of the restructuring economy, the increased individualization of society, the weakness of organized labour and the shift in societal perceptions concerning risk, together make for a challenging scenario in which labour inspectorates are required to operate. It is also one in which some fundamental rethinking of their role to take account of these changes is necessary.

\section{THE FOCUS OF THE STUDY}

The extent to which this rethinking and change of orientation for labour inspection has occurred, the effects it has had on the policies and practices of inspectorates, and on the impact of their work, and the possible need for further rethinking of the role of labour inspection, are among the issues addressed in this study. The study presents an historical and developmental perspective on regulatory inspection of OHS and its management during a time of major change. Its focus is essentially twofold. It examines the implications for OHS inspection of the shift from specification to processbased regulation, in which attention has been increasingly directed to the means of managing health and safety more systematically. At the same time, however, its scrutiny of this issue keeps in mind that in advanced market economies both the origins and implementation of this regulatory shift have been strongly influenced by implications of wider changes in the structure and organization of work that are linked to political and economic responses on the part of both states and the societies they govern to the challenges presented by the globalized economy. The central tenet of the thinking presented in the following pages therefore is that meaningful analysis of the current role of labour inspection must take full account of the interplay between these two issues if a useful understanding of its effectiveness in preventing or ameliorating harm arising from work in modern societies is to emerge.

In the case of the relationship between inspection practice and regulatory emphasis on systematic OHSM there is clearly an awareness of the need of a shift of focus from specification to process-based approaches evident in modern inspection theory. As von Richthofen $(2002,205)$ notes, 
the 'traditional approach whereby inspectors aimed simply to identify legal irregularities and then give advice or impose sanctions, depending on the seriousness of the offence, is increasingly discredited'. The challenge for contemporary OHS inspectorates is to change their inspection and enforcement approaches to inspect systematic OHSM. In this approach, the traditional focus on hazardous conditions and work practices is not abandoned but these conditions are now regarded as signals of weaknesses in OHSM and part of the 'evidence' of the effectiveness of OHSM. Further, the inspectorates not only have to inspect workplaces but also to develop strategies to motivate duty holders to develop their approaches to systematic OHSM, using not only threats of sanctions, but also the commercial self-interest of management, and by demonstrating the efficiency and effectiveness of the OHSM approach (von Richthofen 2002, 208).

But such prescriptions on the part of the theorists of inspection can also be viewed as further evidence of the freedom of capital to dictate the conditions of engagement with an increasingly weakened form of state regulation. As more recent accounts from the ILO acknowledge (Casale and Sivananthiran 2010):

... there is widespread concern that labour inspection services in many countries are not able to carry out their roles and functions ... In many countries, the labour inspectorate is trying to find a new balance between protection of the interests of social justice and fairness on the one hand and economic efficiency in the interests of competitiveness and enterprise growth on the other [our italics].

What actually occurs in inspection practice, however, is little documented and it is for this reason that the chapters in the present volume reporting research findings on these issues from Sweden and Australia are especially significant.

The central question for our research therefore concerns how regulatory inspectorates and their inspectors have responded to the changes in the environments in which they are required to seek compliance with regulatory standards on (managing) health and safety at work. Put in a wider social and economic context, this question embraces a consideration of the political economy of regulation and the impact of business, work and societal reorganization on regulatory inspection, which is acknowledged to be a necessary part of the implementation of regulation in all of the countries studied.

Subsidiary questions necessarily concern the significant features of these environments and their influences - as well as those of the structure and organization of inspection itself. In the case of the latter they involve, among other things, analysis of: 
- trends in the resourcing of inspection, the organizational structures for the delivery of inspection, and the training and tools for inspection that aim to broaden traditional technical-legal competence to also cover aspects of organization and management;

- what is inspected, how inspection is undertaken, both in relation to systematic OHSM, and in relation to specific cases such as stress management, managing hazardous substances, ergonomic issues and so on;

- the relationship between inspection and inspectors and other relevant actors, both within the workplace and in economic or social relation to it;

- the reach of inspection and the extent to which it is relevant to the experiences of various groups of 'vulnerable' workers; and

- how inspection is governed and how the regulator approaches setting inspection policy priorities.

To examine these questions we will scrutinize aspects of the inspection of systematic OHSM in different countries and consider comparatively the impact of political and economic change on the operation of one of the oldest forms of state regulatory intervention. At the same time, we take account of the potential of emergent social interest groups in civil society to support inspection in the wake of the reduced power of trades unions, and consider the potential ways labour inspectorates might work with such groups - as well as with traditional OHS actors such as unions and employer organizations - to enhance and support the role of labour inspection in the new economy.

We think such scrutiny has the potential to make a useful contribution at several levels. First, it offers the possibility to say something helpful about 'what works' and what supports it in the inspection of OHSM in the modern world of work. Second, it presents an understanding of the underlying contexts in which inspection is governed and which influence its operation in the changing political and economic environments characterizing advanced market economies. Third, it allows for some reflection on the nature of these societies, the interactions between social, political and economic interests within them, and their consequences for the protection of the labour and its productive potential that lies at the heart of their economic sustainability. At its core therefore, the theoretical remit of the book is more wide reaching than is suggested by its substantive focus on the implications of change for regulatory inspection of the contemporary emphasis on management of health and safety at work. It concerns the political economy of regulation in modern capitalist societies and the 
relationship between capital, labour and the state in post-industrial societies, in which these actors attempt to come to terms with the consequences of change that are wrought in an increasingly globalized economy. In this respect its attention to the causes and effects of developments in regulatory style and inspection in health and safety at work presents a case study of the relationship between business reorganization, societal values and the role of the state.

\section{THE STRUCTURE OF THE STUDY}

Comparative international studies in the field of labour inspection are rare. The few that exist tend to dwell on the evident infrastructural and policy contrasts between national regulatory and inspection systems. While not denying the importance of such descriptions, the present account takes a somewhat different approach.

The following chapters are the result of a selective and issue-based examination, through the medium of nationally based case studies, of a range of issues that illustrate the contexts, strategies and practices involved in regulatory inspection of approaches to managing health and safety in the face of change. Our account is structured into three parts. In Part I, Chapters 2 and 3 provide an overarching socio-legal analysis of the background to current thinking on regulation and OHSM and an identification of the issues and contexts that are of concern in the present study. The subsequent eight chapters that make up Part III of the book each addresses one or more aspect of these issues within the national contexts of five different countries. They are therefore country specific in terms of detail, but internationally relevant in terms of analysis. Part III concludes the book with two chapters that draw together this analysis and discuss its implications for the future of regulatory inspection of OHSM in the changing world of work.

There is no accepted approach to OHS inspection. ILO Convention 81 on labour inspection provides for a basic set of rules for inspection and bodies such as the EU Committee of Senior Labour Inspectors (SLIC) and the International Association of Labour Inspectors (IALI) provide support for international liaison, common understandings and joint approaches to shared problems between inspectorates. But despite this, beyond general principles, there is no universal model for regulatory inspection of health and safety at work applied consistently across national borders. Not surprisingly, given the differences in the national infrastructures in which health and safety is regulated, there is considerable variation of detail between countries. This is not only in terms of the definition of the subject 
matter addressed by labour inspection, as we have already suggested, but also in relation to the detail of how it is addressed, the resources devoted to inspection, the structure of regulatory inspectorates, their position within public administration and in relation to the legal system, as well as in the nature of the populations covered by inspection. In the following chapters, we outline some of the significant features of the different regulatory inspection systems for OHS in Australia, Sweden, the UK, Québec and France, and locate them within the wider political and economic contexts in these countries, acknowledging the importance of differences in these systems and their contexts in terms of the implications they may have for practice. We then look in more detail and a range of issues of context and practice that are the focus of the present study.

Labour inspection and OHSM in Australia is the first of the book's case studies and the focus of Chapters 4 and 5. These chapters are based on recent empirical research undertaken by the authors on the operation of labour inspection in Australia. Chapter 4 describes the political, economic and regulatory context of inspection, and confirms the major features of the shift from OHS specification standards to performance and processbased standards that has taken place in Australia since the 1970s. Then, using empirical data from field studies of inspection practice Chapter 5 analyses the impact of this shift on inspectors, including the way the inspectorates are recruited, structured, resourced and trained, and the consequences for policies on inspection itself. It looks in some detail at the research evidence collected from several Australian states concerning how inspectors actually undertake inspection of systematic approaches to OHSM and discusses the results of the authors' investigation in terms of the factors that would seem to most influence the extent of this practice. The chapter further considers the impact of changes in enforcement policies on the nature of inspection practice, including comparisons of the use inspectors made of both specification and process-based standards, as well as of various legal and administrative sanctions that are available to them during their work. The chapter looks particularly at practices in relation to plant and equipment, manual handling and ergonomic issues, hazardous substances, changed work arrangements, systematic OHSM and upstream duty-holders (designers, suppliers and manufacturers of plant and substances) - thus analysing inspection practices in relation to both longstanding and relatively new areas of OHS regulation.

The second empirical study specifically on labour inspection and its role in systematic OHSM is presented in Chapters 6 and 7. These chapters report on a study of how the Swedish Work Environment Authority implemented the statutory arrangements for Systematic Work Environment Management that date from the early 1990s. As with the case studies 
in other countries, the chapters first outline the economic, political and regulatory context of provisions for regulating systematic work environment management in Sweden, before focusing on an empirical study of labour inspection itself. They usefully illuminate some differences between Anglo-centric models of the contexts of labour inspection, that dominate the socio-legal literature discussed in Chapter 2, and the experience of compromise between capital, labour and the state that has helped to moderate how labour inspection works in Sweden. Using material gathered and analysed during recent empirical study, the chapters go on to demonstrate the impact of these factors, as well as those of the changing world of work, on the operation of regulatory inspection of systematic work environment management, both generally and in relation to specific issues such as the management of psychosocial risks. They examine the strategies and activities of the Swedish authority and its inspectors in two districts covering a wide range of private and public sector workplaces. The chapters draw on qualitative empirical findings gathered from extensive interviews and observations of regulatory agency inspectors undertaken during their inspection visits to workplaces as well as from interviews with their managers, and with representatives of employers and trade unions. They consider both the direct and indirect roles of inspectors in the promotion of approaches to systematic work environment management, and discuss their findings in the broader context of structural and organization change and in relation to the changing background to Swedish OHS politics.

The third national case study, presented in Chapters 8 and 9, is from the UK. More has already been written about the inspection of health and safety in the UK than in any other country in the book, and as a result, until relatively recently, writing and theorizing based on UK studies constituted a substantial part of the socio-legal literature around regulatory inspection of health and safety at work.

The two UK chapters review what is known about the practice of inspecting health and safety management in the UK. They consider the contexts in which strategies to achieve this have been adopted by policymakers and their significance in determining the approach of field inspectors to achieving compliance from duty-holders. The chapters' thesis acknowledges the central position occupied by these ideas in the aims of UK regulatory approaches but argues that the approach of inspectors towards their practice is influenced not only by the nature of these aims but also by the wider realities in which they are applied. To appreciate this means taking account of the major economic changes that have taken place in the UK since the current regulatory measures on health and safety management were adopted, the policy responses to these changes and their political contexts, including issues of resourcing, deregulation and 
'business-friendly' politics. The chapters explore the impact of these factors on inspection and ask whether a focus on regulating health and safety management can really be claimed to be central in current regulatory policy and practice.

Chapter 10 traces the implementation of a mandatory programme for more systematic management of OHS under the legal provisions introduced in Québec in 1979 and considers the implications this had for inspection practice. The chapter first reviews the political and economic context of regulatory inspection, but the focus for the case study approach taken here is with the trajectory of development and implementation of a regulatory strategy to achieve systematic OHSM, against the background of the economic, political and regulatory factors that influenced it and which also influenced the ways in which labour inspection responded. It is therefore based on the analysis of documentary sources of evidence accumulated over the past 30 years that provide a record of how these wider changes impacted upon the implementation and operation of a particular legislative strategy.

Using both primary and secondary sources of empirical data, Chapter 11 presents a powerful case study on the hidden health effects of outsourcing in France. First it observes the experience of transposition of the EU directives in France, both for occupational health in its general aspects and, more specifically, regarding exposure to carcinogens, in the broad context of the 'new approach' for systematic OHSM. It then addresses how the labour inspectorate has responded to the challenge of an increasingly inaccessible workforce, represented for example by subcontracted workers, many of whose employment conditions are the results of the outsourcing strategies of large organizations. Using empirical data on the incidence of cancer and the employment records of its victims, Thébaud-Mony highlights the existence of significantly higher risk among vulnerable precarious workers, the combination of vulnerability and invisibility of such groups and the considerable challenge that the restructuring and business reorientation that is largely responsible for this presents for inspection of systematic approaches to OHSM. She goes on to consider, through the examination of a series of cases involving a national campaign on cancer prevention conducted by the Labour Inspectorate, the practices of labour inspection in one region of France, a prosecution in the case of asbestos exposure in a major company, and the experience of precarious workers in the chemical and construction industries. The analysis of these different situations further demonstrates the tragic and very real consequences of the regulatory inspectorate's failure to address the challenge sufficiently. 
The final two chapters that make up Part III of the book draw together the themes that have emerged from the national case studies. Chapter 12 summarizes the main findings of the national case studies and examines them from several different analytical perspectives comparing and contrasting the development of OHSM regulation and approaches to enforcement and compliance promotion in different countries, as well as features of the infrastructure and support for regulatory inspection and the roles of other actors in approaches to achieving compliance with OHSM requirements. These perspectives lead to exploration of several issues that emerge from the national case studies, that are taken up in the final chapter of the book and that can be seen as both consequences and responses to the political and economic contexts in which regulatory inspection of OHSM is set and to the changes brought about by economic restructuring in advanced market economies. They include, for example, changes in the balance of private/public regulation; the role of certification; procurement and supply chains in supporting good practice on OHSM; the issue of precarious work; access and hard to reach groups in the new economy; the increasing breadth of the potential coverage of management issues in relation to health, safety and well-being; as well as the blurring of boundaries between work and workplace by restructuring and reorientation of business strategies. How regulatory inspectorates respond to these issues is a focus for discussion in this and Chapter 12 and the extent to which the case studies provide evidence of successful strategies or otherwise is explored. A further comparative strand for discussion in the concluding chapter concerns recent public and policy discourse on work and wellbeing, its implications for labour inspection and its relationship to discourse concerning understandings of workplace risks, how they are best controlled and the role of regulatory inspection in this respect.

Discussion of these issues leads to some conclusions concerning the compatibility of the relationship between business strategies pursued by capital on a global scale, their facilitation by governance at national levels, and the role of regulatory inspection intended to protect workers from harm arising from their work. In so doing, it also helps to remind us why in the twenty-first century, a focus on regulatory inspection of health and safety management remains as powerful a tool for social analysis of the pressing issues of work and well-being in current society, as it was when such inspection was first introduced during the nineteenth century. 